\title{
Perception of Reasons of Decision Making for Home Hospice, Benefits and Difficulties in Home Hospice Care by Family Caregivers
}

\author{
Michiyo Ando', Hiroko Kukihara², Mayumi Yamamoto ${ }^{3}$, Yasuyoshi Ninosaka4, Naoyuki Saito ${ }^{5}$ \\ ${ }^{1}$ Faculty of Nursing, St. Mary's College, Kurume City, Fukuoka, Japan \\ ${ }^{2}$ Faculty of Nursing, Fukuoka University, Fukuoka, Japan \\ ${ }^{3}$ School of Nursing at Fukuoka, International University of Health and Welfare, Fukuoka, Japan \\ ${ }^{4}$ Ninosaka Clinic, Fukuoka, Japan \\ ${ }^{5}$ Saito Clinic, Kurume, Japan \\ Email: andou@st-mary.ac.jp
}

How to cite this paper: Ando, M., Kukihara, H., Yamamoto, M., Ninosaka, Y. and Saito, N. (2019) Perception of Reasons of Decision Making for Home Hospice, Benefits and Difficulties in Home Hospice Care by Family Caregivers. Open Journal of Nursing, 9, 1013-1021.

https://doi.org/10.4236/ojn.2019.910075

Received: September 19, 2019

Accepted: October 19, 2019

Published: October 22, 2019

Copyright $\odot 2019$ by author(s) and Scientific Research Publishing Inc. This work is licensed under the Creative Commons Attribution-NonCommercial International License (CC BY-NC 4.0). http://creativecommons.org/licenses/by-nc/4.0/ cC) (i) (8) Open Access

\begin{abstract}
Objective: Home hospice is one of the most important places to spend time at the end of life. It is necessary to clarify the perception of home hospice for family caregivers in order to choose home hospice. The aim of the study was to examine the perceptions of family caregivers about the reasons of decision making for home hospice care, benefits, difficulties with home hospice, and copings. Methods: Ten family caregivers who were taking care of a patient with a terminal illness at home at the time of the study participated voluntary. They participated in two interviews in the narrative approach. In the first session, they narrated reasons of decision making for home hospice, benefits, difficulties, and copings. In the second session, they narrated importance or growth in self. We analyzed narratives in the first session using qualitative analysis. This study was approved by the Ethical Board at St. Mary's College. Results: Categories of the reasons for the decision making to undergo home hospice were "Being natural to take care of a loved one at home" or "Home hospice matching a family caregiver's life". Categories of benefits at home hospice were "To strengthen family's ties" or "Both a loved one and a family spending time together". Categories of difficulties were "Difficulty of economic problems" or "Difficulties of mental and physical symptoms". Conclusion: We concluded that family caregivers perceived benefits and difficulties, and they could cope with difficulties, though spiritual pain remained. We need continuous support for family caregivers at home hospice.
\end{abstract}

\section{Keywords}

Home Hospice, Decision, Benefits, Difficulties, Family Caregivers 


\section{Introduction}

Recently the elderly population is increasing in Japan and this tendency is similar to some other countries. It is important for people to decide how to live and die related to Good Death. About 70\% people want to live and die in their home [1], however, only about $20 \%$ died in their home [2]. That is, their hope was not attained. This tendency is also similar to United Kingdom according to Jack, et al. [3].

Although patients hope to come home from hospitals, family caregivers also have difficulties. Ando, et al. [4] examined difficulties for bereaved families of home hospice, and from the Family Difficulty Scale (FDS), the FDS score for "Patient's pain and condition" was the highest, followed by "Caregivers did not want home care" and "No support from others." These results suggest that the condition of the patient, the view of the caregiver on home care, and the absence of other support are important factors contributing to difficulties of family caregivers. Moreover, family caregivers perceived that they experience physical, psychological, and/or spiritual problems [5]. However, this study was conducted for bereaved families after 6 months of loved ones' death and their impression might be forgotten, and it was not clear how family caregivers who were taking care at the present perceived home hospice. It is important to clarify the perception of family caregivers who were taking care at the present the reason why they decide to take care of a loved one at home hospice, benefits and difficulties using a narrative approach. White and Epson [6] demonstrated a narrative therapy, in which people create meaning of illness, suffering, and death through a narrative, by telling a story [7] [8].

Then the purpose of this study was to clarify reason for decision of family caregivers to use home hospice, benefits, difficulties, and coping methods for difficulties with home hospice.

\section{Methods}

\subsection{Participants}

We attempted to recruit 12 family caregivers, two declined to participate, and ten participated. The patients were in three kinds of clinics in Japan (Table 1). The patients whom family caregivers took care of had low physical power like Performance Status (PS) [9] from 2 to 4. The stage of a patient's cancer was " 4 " or recurrence. The inclusion criteria were a family member who was taking care right now via home hospice, was aged $\geq 20$ years old, and could discuss their situation for 60 minutes. The exclusion criteria were patients with cognitive impairment or serious mental illness.

\subsection{Procedure}

The primary physician introduced the study to a family caregiver who met the inclusion criteria. Family caregivers who showed interest were registered and the researchers sent a letter about the research. After sending a letter, the researcher 
Table 1. Background of family caregivers.

\begin{tabular}{|c|c|c|c|c|c|c|c|c|c|}
\hline ID & Age & Gender & $\begin{array}{l}\text { Relationships } \\
\text { for a patient }\end{array}$ & Patients' disease & Disease stage & $\begin{array}{l}\text { PS of a } \\
\text { patient }\end{array}$ & $\begin{array}{l}\text { Duration } \\
\text { of care }\end{array}$ & Substitute & $\begin{array}{c}\text { Burden } \\
(1-5)\end{array}$ \\
\hline ID 1 & 60 & $\mathrm{~F}$ & Wife & Lung & 4 & 4 & 2 years & $\mathrm{N}$ & 2 \\
\hline ID 2 & 70 & $\mathrm{~F}$ & Child & Colon & 4 & 4 & 1 year & $\mathrm{N}$ & 2 \\
\hline ID 3 & 50 & $\mathrm{~F}$ & Wife & ATL & 4 & 4 & 2.5 years & $\mathrm{N}$ & 2 \\
\hline ID 4 & 50 & $\mathrm{~F}$ & Wife & Lung & 4 & 2 & 4 month & $\mathrm{N}$ & 2 \\
\hline ID 5 & 60 & $\mathrm{~F}$ & Child & Heartfailure & Terminal & 2 & 6 years & $\mathrm{N}$ & 1 \\
\hline ID 6 & 80 & $\mathrm{~F}$ & Wife & Stomach & 4 & 3 & 2 years & $\mathrm{Y}$ & 1 \\
\hline ID 7 & 30 & $\mathrm{~F}$ & Child & Stomach & 4 & 2 & 2 years & $\mathrm{N}$ & 2 \\
\hline ID 8 & 60 & $\mathrm{~F}$ & Wife & Prostate cancer & Recuurence & 3 & 1 years & $\mathrm{N}$ & 3 \\
\hline ID 9 & 70 & $\mathrm{~F}$ & Wife & Labor & Recuurence & 3 & 2.5 years & $\mathrm{N}$ & 3 \\
\hline ID 10 & 30 & $\mathrm{~F}$ & Child & Lung & 4 & 4 & 4 month & $\mathrm{Y}$ & 4 \\
\hline
\end{tabular}

explained the details of the study to the candidate via telephone. If he or she agreed to participate, they decided the place and time for an interview. The interviewer visited a family caregiver's home or a clinic, explained about the research again, and received informed consent after agreement for participation.

In the Narrative approach, there were two sessions. We prepared some questions referring to previous studies to promote the family caregiver's narratives [10] [11].

In the first session, there were the following questions, 1) For what reasons did you decide to take care of your loved one (patient) at home hospice?, 2) What are benefits of home hospice?, 3) What are difficulties in taking care of the patient with home hospice? In the second session, there were some other questions related to importance, growth in self or future, which were reported on another occasion. Then in this study, we analyzed narratives about the first session. With participants' permission, their narratives were recorded on IC recorders. Before the first session and after the second session, the participants completed questionnaires. Each session lasted about 60 minutes. They completed some psychological questionnaires; these quantitative results are reported on another occasion. This study was approved by the ethical boards of St. Mary's College.

\subsection{Analysis}

For the narrative data, we employed "qualitative analysis" by Funashima [12] based on the work of Berelson [13] which involves creating codes, subcategories and categories. These narratives were edited into the shortest statement without losing meaning and coded into one subcategory along with similar statements. Similar subcategories were then integrated into one category. To maintain reliability, categorization and coding were validated independently by researchers. Inconsistencies were discussed and negotiated until agreement was reached. 


\section{Results}

\subsection{Decision Reasons for Home Hospice}

We show the subcategory as $<>$ and category as " ". About the reasons for the decision to use home hospice, we chose four categories (Table 2). A category 1) "Being natural to take care of a loved one at home" included subcategories like $<$ I thought that I would take care of the patient because we are mother and child $>$ or $<$ We lived together and it was natural $>$. The category 2) "Home hospice matching a family care giver's life" included subcategories like < It was difficult for me to take care of a loved one both at home and in a hospital $>$. The category 3) "Feeling that I can take better care of a loved one at home than the care given at a hospital" included sub-categories like "A loved one hoped to come home." or "I disliked detainment in a hospital". The category 4) "Not being able to agree with a treatment policy or not being able to adapt to hospital life" included sub-categories like $<$ A loved one's expectation for treatment did not agree with a hospital policy>.

\subsection{Benefits with Home Hospice}

About benefits with home hospice, there are six categories (Table 3). The category 5) "Having a sense of security" included subcategories like <Being together offers a sense of security $>$ or $<$ I can give back to my husband $>$. The category 6) "To strengthen a family's ties" included subcategories like <Children

Table 2. Reasons for the decision of family care givers to use home hospice.

Samples of code Sub-category

Category

- It was natural for me to take care of the patient myself.

- We are mother and child.

- A loved one and I have lived together for a long time and it was natural.
- I thought that I would take care of the patient because we are mother and child.

- We lived together and it was natural.
1) Being natural to take care of a

loved one at home.
- I take care of my father in my home.

- In addition to this, taking care of a loved one in a hospital was difficult.
- It was difficult for me to take care of a loved one both at home and in a hospital.
2) Home hospice matching a family care giver's life.
- My husband was a stranger and felt alone.

- He did what he liked.

- It seemed difficult for him to

- He was detained for some reasons.

- I was shocked.

- At home, I do not need to detain my loved one.

- In a hospital, bed sheets are not always changed.
- A loved one couldn't make a good relationship with others.

- Hospitalized life with rules seemed to be hard for a patient.

- A loved one hoped to come home.

- I disliked detainment in a hospital.

- I felt a care shortage in a hospital.
3) Feeling that I can take better care of a loved one at home than the care given at a hospital.
- A loved one asked for a tailor made anti-cancer agent.

- A physician did not agree with it.

- A loved one used some kind of anti-cancer agent and had severe side effects.
- A loved one's expectation for treatment did not agree with a hospital policy.

- I feltl imitations in medical treatment.
4) Not being able to agree with a treatment policy or not being able to adapt to hospital life. 
Table 3. Beneficits of home hospice for family caregivers.

\begin{tabular}{|c|c|c|}
\hline Samples of Code & Sub-category & Category \\
\hline $\begin{array}{l}\text { - Getting hospitalized enhanced separation } \\
\text { time. } \\
\text { A loved one (husband) took care of my } \\
\text { mother who had dementia and I } \\
\text { can give back. }\end{array}$ & $\begin{array}{l}\text { - Being together offers a sense of security. } \\
\text { - I can give back to my husband. }\end{array}$ & 5) Having a sense of security. \\
\hline $\begin{array}{l}\text { - } \quad \text { My daughter came to me frequently. } \\
\text { - } \quad \text { Samily members collaborated together. } \\
\text { - } \quad \text { After getting an illness, family care givers } \\
\text { began to talk. }\end{array}$ & $\begin{array}{l}\text { - Children collaborated. } \\
\text { - Someone said something to a patient. } \\
\text { - Family caregivers began to } \\
\text { discuss nursing care. }\end{array}$ & 6) To strengthen a family's ties. \\
\hline $\begin{array}{l}\text { I am satisfied with cleaning the sheets of a } \\
\text { loved one. } \\
\text { - I can feel relieved. } \\
\text { - A loved one enjoys the scene of my garden. }\end{array}$ & $\begin{array}{l}\text { - I can clean the sheets anytime. } \\
\text { - I can feel relieved. }\end{array}$ & 7) Being satisfied with care. \\
\hline $\begin{array}{l}\text { - A loved one and their family spend } \\
\text { time together. } \\
\text { - Family members went on a trip to Okinawa } \\
\text { and made memories. }\end{array}$ & $\begin{array}{l}\text { - Both a loved one and the family } \\
\text { caregiver were relaxed. } \\
\text { - I can remember the trip. }\end{array}$ & $\begin{array}{l}\text { 8) Both a loved one and a family } \\
\text { Spending time together. }\end{array}$ \\
\hline $\begin{array}{l}\text { - A medicine was effective for a loved one (my } \\
\text { husband). } \\
\text { - I could go to the gym. } \\
\text { - We talked about new themes. }\end{array}$ & $\begin{array}{l}\text { - A medicine was effective. } \\
\text { - A loved one felt well and I enjoyed my } \\
\text { time. }\end{array}$ & 9) A care giver having their own time. \\
\hline $\begin{array}{l}\text { - My end was on the way. } \\
\text { - I went to a class on cancer and resolved my } \\
\text { questions. }\end{array}$ & - I am thinking of the end of my life. & $\begin{array}{l}\text { 10) Promoting thinking of my own } \\
\text { nursing care. }\end{array}$ \\
\hline
\end{tabular}

collaborated $>$ or $<$ Someone said something to a patient $>$. The category 7) "Being satisfied with care" included subcategories like $<$ I can clean the sheets anytime $>$ or $<$ I can feel relieved $>$. The Category 8) "Both a loved one and a family spending time together" included subcategories like $<$ Both a loved one and the family caregivers were relaxed $>$ or $<$ I can remember the trip $>$. The category 9) "A caregiver having their own time" included subcategories like $<$ A medicine was effective $>$ or $<$ A loved one felt well and I enjoyed my time $>$. The category 10) "Promoting thinking of my own nursing care" included subcategories like $<\mathrm{I}$ am thinking of the end of my life $>$.

\subsection{Difficulties with Home Hospice and Coping}

About difficulties and coping, there are seven categories (Table 4). The category "11) Difficulties of economic problems" included subcategories like <I lost income $>$ or $<$ I have to pay tax $>$. Family caregivers had "12) Difficulties with mental and physical symptoms" and coped by "13) Being able to consult a visiting physician and nurse >". However, family caregivers had "14) Difficulty of coping with a patient's spiritual pain" and they did not cope with this. 
Table 4. Difficulties and coping methods by family care givers.

\begin{tabular}{|c|c|c|}
\hline Samples of code & Sub-category & Category \\
\hline $\begin{array}{l}\text { I quit my job for nursing care. } \\
\text { - I have to pay property tax. }\end{array}$ & $\begin{array}{l}\text { - I lost income. } \\
\text { - I have to pay tax. }\end{array}$ & 11) Difficulties of economic problems. \\
\hline $\begin{array}{l}\text { - I had difficulty with a patient's delirium. } \\
\text { - I asked the physician for a drug to get better. } \\
\text { - I had difficulty with a patient's loss of } \\
\text { appetite. } \\
\text { - The primary physician cheered me on. } \\
\text { - The visiting nurse visited every day. } \\
\text { - A loved one had edema and suffered. }\end{array}$ & $\begin{array}{l}\text { - I had trouble with a patients s mental } \\
\text { symptoms. } \\
\text { - It was treated by medication. } \\
\text { - I had trouble with a loved one's physical } \\
\text { problems. } \\
\text { - The primary physician cheered me on. } \\
\text { - The visiting nurse came to me every day. } \\
\text { - A nurse's massage relieved edema. }\end{array}$ & $\begin{array}{l}\text { 12) Difficulties with mental and } \\
\text { physical symptoms. } \\
\text { 13) Being able to consult a visiting } \\
\text { physician and nurse. }\end{array}$ \\
\hline $\begin{array}{l}\text { - A loved one wanted to talk at midnight. } \\
\text { - A loved one apologized for needing nursing } \\
\text { care. } \\
\text { - A family member was irritated. }\end{array}$ & $\begin{array}{l}\text { A loved one felt loneliness and sorrow } \\
\text { for being a burden. } \\
\text { - A patient was caused panic from } \\
\text { loneliness. }\end{array}$ & $\begin{array}{l}\text { 14) Difficulty of coping with a } \\
\text { patient's spiritual pain. }\end{array}$ \\
\hline $\begin{array}{l}\text { - A loved one got angry with family caregivers } \\
\text { when he was not well. } \\
\text { - A primary physician understood a loved one's } \\
\text { emotions and spoke to them. } \\
\text { - A patient did not know the time left. } \\
\text { - A loved one considered the timing of } \\
\text { truth-telling. }\end{array}$ & $\begin{array}{l}\text { - A loved one was angry and coped with } \\
\text { physician's intervention. } \\
\text { - A physician considered the timing of } \\
\text { truth-telling. }\end{array}$ & $\begin{array}{l}\text { 15) A patient getting angry with a } \\
\text { family member. } \\
\text { 16) Consulting a physician and } \\
\text { settling down. }\end{array}$ \\
\hline $\begin{array}{l}\text { - Preparing a loved one's meal limited my time. } \\
\text { - I drove instead of my husband. } \\
\text { - } \text { My husband thought deeply. } \\
\text { - I paid attention to conversations to not hurt a } \\
\text { loved one's heart. } \\
\text { - I did not agree with a patient. } \\
\text { - I drove and changed my mood. } \\
\text { - I can't walk freely in my house. } \\
\text { - I used a walker. }\end{array}$ & $\begin{array}{l}\text { - Time was sometimes limited. } \\
\text { - I covered what he was not able to. } \\
\text { - I paid attention to conversations with a } \\
\text { loved one. } \\
\text { - I found solutions for my stress. } \\
\text { - Family caregiver had a back problem. }\end{array}$ & $\begin{array}{l}\text { 17) Stress of nursing care and } \\
\text { finding solutions. } \\
\text { 18) Caregivers' physical problems. }\end{array}$ \\
\hline
\end{tabular}

Also, family caregivers experienced difficulties like 15) "A patient getting angry with a family member" and coped by 16) "Consulting a physician and settling down". They felt the 17) "Stress of nursing care and finding solutions" such as $<$ Time was sometimes limited $>$ or $<$ I paid attention to conversations with a loved one $>$. However, family caregivers had difficulties due to 18) "Caregivers' physical problems".

\section{Discussion}

\subsection{Reason of Decision Making for Home Hospice}

About decision reasons for home hospice, the category of "Being natural to take care of a patient at home" was related to the Japanese traditional culture partly. In the past, in Japan, some generations had lived together and took care of their parents. This tradition may remain sometimes. In addition to the tradition, there is another factor such as relationships between family caregivers and 
a patient. To continue care via home hospice, the relationships before beginning care may influence the decision.

"Feeling that I can take better care of a loved one at home than the care given at a hospital" shows the strong intention of a family caregiver to take care of the patient. Sometimes patients return to the hospital [14] [15], but the hope or intention of family caregivers may promote home hospice.

About the category "Not being able to agree with a treatment policy or not being able to adapt to hospital life", a patient's needs and the treatment policy of a hospital are sometimes different. Therefore, we need to consider carefully between the choices of hospital or home hospice.

\subsection{Benefits and Difficulties}

Categories about benefits were "Having a sense of security" "Being satisfied with care" "To strengthen a family's ties" "Both a loved one and a family can spend time together" "A caregiver having their own time" and "Promoting thinking of my own nursing care".

Family caregivers can take care as much as possible and feel a sense of security. Moreover, they can spend more time with a patient at home, strengthen a family's ties and feel satisfaction with home hospice. This perception is supported by bereaved families who used home hospice according to Ando et al. [16]. McDonald et al. [17] investigated the quality of life of caregivers and found some themes like "renegotiating relationships" or "maintaining resilience," which are beneficial points. Related to "A caregiver having their own time," at first family caregivers were not used to taking care of a patient, and they enjoyed their free time.

About difficulties, there were mental and physical symptoms like pain, loss of appetite or delirium. These difficulties are similar to results of previous studies. Phongtankue, et al. [5] showed that family caregivers in home hospice perceived three types of crises: patients' signs and symptoms (51.67\%), patients and/or caregivers emotional distress (29\%), and caregivers burdens (13\%). Also, Han et al. [18] showed that hospice nurses need to assess and address caregiver's pain management challenges during home visits. In this study, when family members confronted mental and physical problems, they consulted a visiting physician or a visiting nurse and difficulties were solved. Family caregivers needed to consult them easily.

Related to mental problem, spiritual pain with home hospice is important. Spiritual pain relates to loss of meaning to live or suffering about death. In the present study, family caregivers experienced difficulty coping with patients' spiritual pain. In a hospital, there are many professions and a patient with spiritual pain may easily experience spiritual care, however, it may be difficult to experience it constantly with in home hospice. Scott, et al. [19] showed that a caregiver's psychological and spiritual distress were particularly dynamic and commonly experienced. As an intervention, Ando et al. [20] showed that the Narra- 
tive Approach via nurses for home hospice may be useful. Also home-based palliative care was perceived to be useful for patients, physicians, nurses, and volunteers. Patients felt that the program enabled them to become more independent and self-reliant [21].

Integrated benefits and difficulties, firstly family caregivers were not used to taking care of a patient at home, and were confronted with some difficulties and solved some problems. Support by visiting physicians and nurses may help them to continue care. However, some difficulties were remained like spiritual pain and much more intervention will be required. Jack, et al. [3] showed, health care professionals perceived that the additional individualized support provided by this service contributed to enabling patients to continue to be cared for and to die their home if that was their choice.

This study has several limitations. The generalizability may be limited because the number of participants was small. To generalize these results, we need to add many more participants.

\section{Conclusion}

We concluded that family caregivers perceived benefits and difficulties, and they could cope with difficulties, though spiritual pain remained. We need continuous support for family caregivers at home hospice.

\section{Conflicts of Interest}

The authors declare no conflicts of interest regarding the publication of this paper.

\section{References}

[1] Choi, J., Miyahita, M., Hirai, K., et al. (2010) Preference of Place for End-of-Life Cancer Care and Death among Bereaved Japanese Families Who Experience Home Hospice Care and Death of Loved One. Support Care Cancer, 18, 1445-1453. https://doi.org/10.1007/s00520-009-0767-3

[2] Ministry of Health, Labor and Welfare (2013) Mitori. (In Japanese) http://mhlw.go.jp/stf/shingikai/

[3] Jack, B.A., Baldry, C.R., Groves, K.E., et al. (2013) Supporting Home Care for the Dying: An Evaluation of Healthcare Professionals' Perspectives of an Individually Tailored Hospice at Home Service. Journal of Clinical Nursing, 22, 2278-2286. https://doi.org/10.1111/j.1365-2702.2012.04301.x

[4] Ando, M., Ninosaka, Y., Okamura, K. and Ishi, Y. (2015) Difficulties in Caring for Cancer Patients at the Endo of Life at Home and Complicated Grief. American Journal of Hospice and Palliative Medicine, 32, 173-177. https://doi.org/10.1177/1049909113514626

[5] Phongtankuel, V., Burchett, C.O., Shalev, A., et al. (2019) Perception of a Home Hospice Crisis: An Exploratory Study of Family Caregivers. Journal of Palliative Medicine, 22. https://doi.org/10.1089/jpm.2018.0511

[6] White, M. and Epson, D. (1990) Narrative Means to Therapeutic Ends. Norton, New York. 
[7] Stanley, P. and Hurst, M. (2011) Narrative Palliative Care: A Method for Building Empathy. Journal of Social Work in End of Life \& Palliative Care, 7, 39-207. https://doi.org/10.1080/15524256.2011.548046

[8] Thomas, C., Reeve, J., Bingley, A., et al. (2009) Narrative Research Methods in Palliative Care Context: Two Case Studies. Journal of Pain and Symptom Management, 37, 788-796. https://doi.org/10.1016/j.jpainsymman.2008.05.006

[9] Oken, M.M., Creech, R.H., Tormey, D.C., et al. (1982) Toxicity and Response Criteria of the Eastern Cooperative Oncology Group. American Journal of Clinical Oncology, 5, 649-656. https://doi.org/10.1097/00000421-198212000-00014

[10] Lloyd-Williams, M., Shiels, C., Ellis, J., et al. (2018) Pilot Randomized Controlled Trial or Focused Narrative Intervention for Moderate to Severe Depression in Palliative Care Patients: DISCERN Trial. Palliative Medicine, 32, 206-2015. https://doi.org/10.1177/0269216317711322

[11] Wise, M., Marchnad, L.R., Roberts, L.J., et al. (2018) Suffering in Advanced Cancer: A Randomized Control Trial of a Narrative Intervention. Journal of Palliative Medicine, 21, 200-2007. https://doi.org/10.1089/jpm.2017.0007

[12] Funashim, N. (2001) Challenges in Qualitative Analysis [In Japanese]. Igakusyoin, Tokyo.

[13] Berelson, B. (1952) Content Analysis.

[14] Phongtankuel, V., Scherban, B.A., Reid, M.C., et al. (2016) Why Do Home Hospice Patients Return to the Hospital? A Study of Hospice Provider Perspectives. Journal of Palliative Medicine, 19, 51-56. https://doi.org/10.1089/jpm.2015.0178

[15] Kawase, K., Knamura, N., Onuki, E., et al. (2017) Difficulties Faced by Family Caregivers for Terminal Cancer Patient Cessation of Home-Based. Palliative Care Research, 12, 194-202. https://doi.org/10.2512/jspm.12.194

[16] Ando, M., Ninosaka, Y. and Okamura, K. (2015) Useful and Difficult Matters on Decision Making in Home Care at the End-of-Life. Japanese Journal of International Nursing Care Research, 14, 87-96.

[17] McDonald, J., Swami, N., Pope, A., et al. (2018) Caregiver Quality of Life in Advanced Cancer: Qualitative Results from a Trial of Early Palliative Care. Palliative Medicine, 32, 69-78. https://doi.org/10.1177/0269216317739806

[18] Han, C.J., Chi, N.C., Han, S., et al. (2018) Communicating Caregivers' Challenges with Cancer Pain Management: An Analysis of Home Hospice Visit. J of Pain Symptom Manage, 55, 1296-1303. https://doi.org/10.1016/j.jpainsymman.2018.01.004

[19] Scott, A.M., Marilyn, K., Kirsty, B., et al. (2010) Archetypal Trajectories of Social, Psychological, and Spiritual Wellbeing and Distress in Family Care Givers of Patients with Mung Cancer: Secondary Analysis of Serial Qualitative Interviews. British Medical Journal, 340, 1-6.

[20] Ando, M., Yamamoto, M., Ninosaka, Y. and Okamura, K. (2019) A Pilot Study of Narrative Approach for Terminally Ill Cancer Patient at Home Hospice. Clinical Case Reports and Review. https://doi.org/10.15761/CCRR.1000383

[21] Philip, R.R., Venables, E. and Manima, A. (2019) "Small Interventions, Big Roles"-A Qualitative Study of Patient, Care-Giver and Health-Care Worker Experiences of a Palliative Care Program in Kerala, India. BMC Palliative Care, 18, 16. https://doi.org/10.1186/s12904-019-0400-2 